\title{
Harmonic stability analysis of multi-paralleled 3-phase PV inverters tied to grid
}

\author{
R.S. Ravi Sankar, K. K. Deepika, A.V. Satyanarayana \\ Department of Electrical and Electronics Engineering, Vignan's Institute of Information Technology, Visakhapatnam, \\ Andhra Pradesh, India
}

\begin{abstract}
Article Info
Article history:

Received Jun 12, 2020

Revised Mar 27, 2021

Accepted Apr 5, 2021

\section{Keywords:}

Distribution generation Grid impedance

Impedance based stability

ABSTRACT

In this paper the harmonic stability is investigated for multi paralleled threephase photovoltaic inverters connected to grid. The causes to harmonically stabilize/destabilize the multi-paralleled PV inverters when tied to the grid is analysed by the impedance-based stability criterion (IBSC). In this paper stability of the system is investigated by varying the grid inductance with constant grid resistance and also by varying load impedance while maintaining grid inductance constant. Stability of the multiple three phase inverters tied to the grid with different grid impedance, inductance value in particular are analyzed. Overall system is stable up to grid inductance of $5 \mathrm{mH}$ even though there is change in load admittance. It is concluded that system stability depends only on grid impedance. It is verified with MATLAB Simulations.
\end{abstract} criterion

Inverter output impedance

Maximum power point tracking

Minor loop gain

Proportional-resonant current

controller

PV array

\section{Corresponding Author:}

R.S. Ravi Sankar

Department of Electrical and Electronics Engineering

Vignan's Institute of Information Technology

Visakhapatnam, Andhra Pradesh, India

Email: satya_ravi2001@yahoo.com
This is an open access article under the CC BY-SA license.

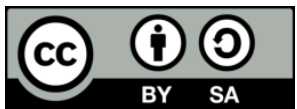

\section{INTRODUCTION}

Proliferation of renewable energy sources is the current scenario to the meet the increasing load demand. When these sources are connected to the grid there is interaction between the LCL filter, grid impedance, and inner current loop of the inverters. Thereby, it causes the harmonic instability [1], [2]. Which further leads to amplification of resonance over the range of frequencies. This sometimes leads to unwanted withdrawal of the PV inverters from the grid [3], [4]. The interaction of the admittances of multiple inverters causes two issues one is amplification of Resonance and seconed one harmonic instability. These two issues are analyzed and answered by means of IBSC analysis. IBSC was applied to design the output filter in chopper circuits [5], [6]. The conversion method for harmonic transfer function-based model for a Voltage source converter into a simple and efficient Single Input Single Output model [7]. Stability characteristics were obtained with the frequency coupling effect. In [8], Impedance model in dq-frame was developed for offshore wind power plant to study the effect of inverters and transmission cables. The analyzed the harmonic stability in modular multilevel based DC systems. It was verified with hardware experimentation as well as simulation. DC impedance model of the system was developed by considering the capacitor voltage fluctuation, harmonic responses [9]. 
In this work, IBSC tool is used in the multi-inverters tied to grid to examine the harmonic stability. The system stability is evaluated by graphical analysis using minor loop gain of the overall system. If the system obeys the nyquiest stability criteria than the system is stable otherwise it is unstable. The concept of passivity-based stability analysis has recently gained attention in control system [10] and from this stability analysis each subsystem has a phase margin lies between $-90^{\circ}$ to $90^{\circ}$. Then the system is stable otherwise system is unstable.

In this paper, Section 2 deals with the Mathematicall modeling of the PV system, in Section 3, the calculation of the Output Impedance of inverter and the modeling of the PR current controller. In Section.4. simulation results of the two case studies are discussed.

\section{MATHEMATICALL MODELING OF PV SYSTEM}

\subsection{Modeling of PV array}

In this study PV array provides the DC voltage to boost converter. Single diode model of a PV Cell is depicated in Figure 1. It represents simple modeling where resistances are neglected [11]-[16]. The parameters of the PV module are shown in Table.1. These are used to simulate the PV array in matlab simulation. two modules are connected in series to give the voltage of $700 \mathrm{~V}$ and the PV current supplied is 40A. The PV power supplied by the inverter is $2 \mathrm{KW}$ even though it is designed for the $14 \mathrm{KW}$. The PV array voltage, current and power wave forms are depicted in Figure 2 to Figure 4.

\subsection{Maximum power point tracking (MPPT)}

PV panel output is highly depending on climatic conditions, extracted maximum power from PV panels. Different MPPT techniques are proposed in literature. For simple implementation, $\mathrm{P} \& \mathrm{O}$ technique is implemented in this paper [17], [18].

Table 1. Specifications of the PV module

\begin{tabular}{lcl}
\hline Parameter & Variable & Value \\
\hline Current at $\mathrm{P}_{\mathrm{Max}}$ & $\mathrm{I}_{\mathrm{m}}$ & $8.30 \mathrm{~A}$ \\
Voltage at $\mathrm{P}_{\mathrm{Max}}$ & $\mathrm{V}_{\mathrm{m}}$ & $30.2 \mathrm{~V}$ \\
O.C Voltage & $\mathrm{V}_{\mathrm{oc}}$ & $37.3 \mathrm{~V}$ \\
S.C Current & $\mathrm{I}_{\mathrm{sc}}$ & $8.71 \mathrm{~A}$ \\
Series Resistance & $\mathrm{R}_{\mathrm{s}}$ & $0.217 \mathrm{ohm}$ \\
Ref. Solar Radiation & $\mathrm{S}_{\mathrm{ref}}$ & $1000 \mathrm{~W} / \mathrm{m}^{2}$ \\
Ref. Temperature & $\mathrm{T}_{\mathrm{ref}}$ & $300 \mathrm{k}$ \\
\hline
\end{tabular}

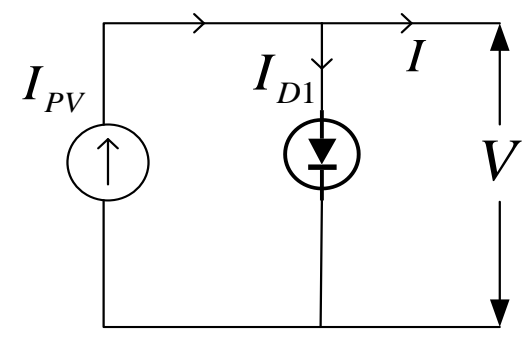

Figure 1. PV cell equivalent circuit

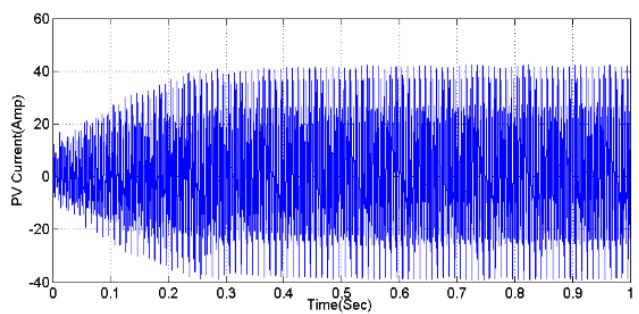

Figure 3. PV current (in amps)

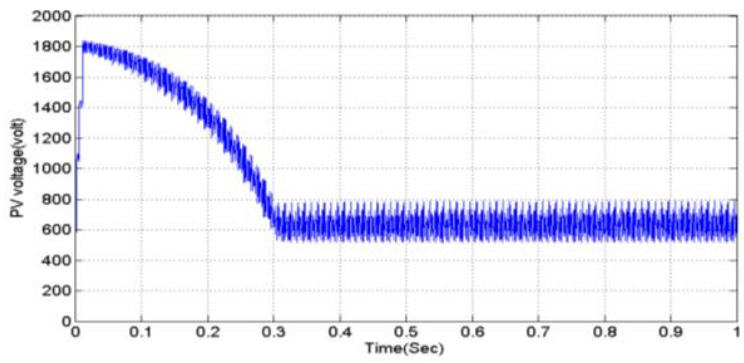

Figure 2. PV voltage (in volts)

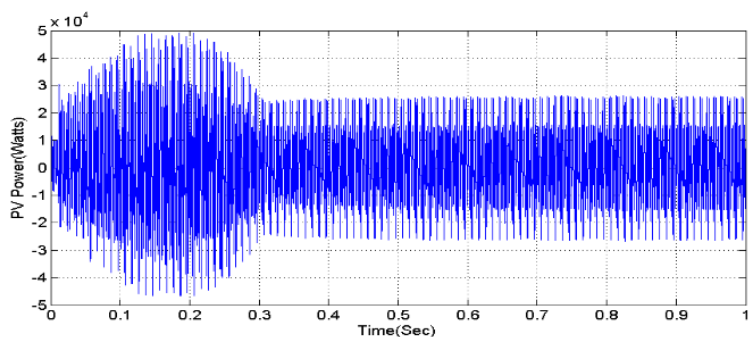

Figure 4. PV power (in watts) 


\section{MODELING OF INVERTER OUTPUT ADMITTANCE}

\subsection{Calculation of inverter output admittance}

The small signal modeling of grid connected inverter is shown in Figure 5. in that PV inverter is tied to the grid, for filtering purpose LCL filter is used. The overall system is represented in block diagrame in Figure 6. In this work PR current controller is taken as current controller [19], [20].

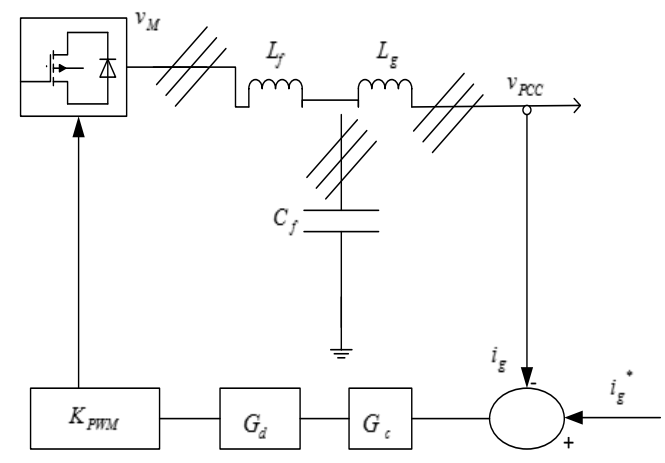

Figure 5. 1-Ph. depication of system

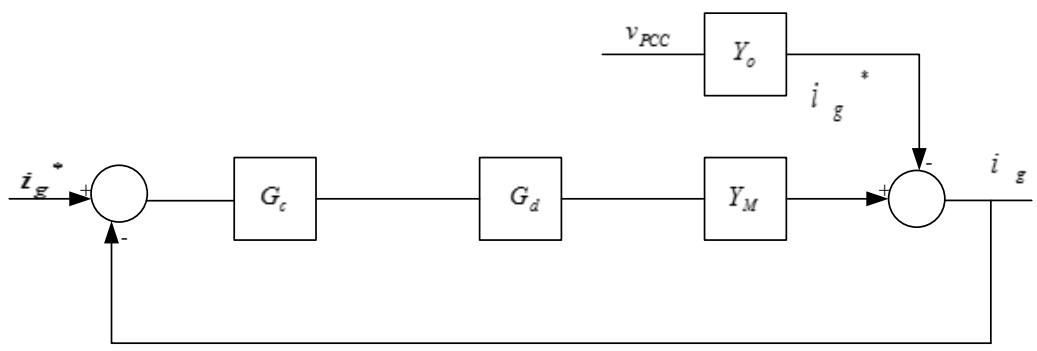

Figure 6. Block diagrame of the system

Where $\left(G_{c}\right)$ Current controller, $\left(G_{d}\right)$ delay gain and $\left(K_{P W M}\right)$ PWM gain are defined as [21], [22]:

$$
G_{C}(s)=K_{1}, G_{d}(s)=e^{-1.5 T_{S} s}, K_{P W M}=1
$$

The converter output admittance is defined as $Y_{C}(s)=\frac{Y_{0}}{1+G_{C} G_{d} Y_{M}}$

The output admittance of LCL filter is given by

$$
Y_{o}(s)=\left.\frac{-i_{g}}{v_{P C C}}\right|_{v_{M}=0}=\frac{s^{2} C_{f} L_{f}+1}{s\left(s^{2} C_{f} L_{f} L_{g}+L_{f}+L_{g}\right)}
$$

The trans admittance of the LCL filter is given by

$$
Y_{M}(s)=\left.\frac{i_{g}}{v_{M}}\right|_{v_{P C C}=0}=\frac{1}{s\left(s^{2} C_{f} L_{f} L_{g}+L_{f}+L_{g}\right)}
$$

Finally, the converter admittance is given by 


$$
Y_{C}(s)=\left.\frac{i_{g}}{v_{P C C}}\right|_{i_{g}{ }^{*}=0}=\frac{Y_{O}}{1+G_{c} G_{d} Y_{M}}=\frac{s^{2} C_{f} L_{f}+1}{s^{3} C_{f} L_{f} L_{g}+s\left(L_{f}+L_{g}\right)+K e^{-1.5 T_{S} s}}
$$

Here $\mathrm{K}_{1}$-Gain of controller, $T_{s}$ - sampling time, $i_{g}$-Grid current, $\mathrm{V}_{\mathrm{M}}$, $\mathrm{V}_{\mathrm{PCC}}$-converter output voltage, PCC voltages, $\mathrm{L}_{f}, \mathrm{Lg}$ - filter inductance value inverter side and grid side.

\subsection{Proportional resonant current controller:}

A proportional resonant (PR) controller exhibits a better steady state and dynamic performance. Input- output relation of an ideal PR controller is expressed by (6) [22], [23]. In the same way, for a non-ideal PR Controller it is given by (7) [24]:

Ideal proportional resonant controller: $G_{P R}(s)=K_{P}+\frac{2 K_{r} s}{s^{2}+\omega^{2}}$

Non- ideal PR controller: $G_{P R}(s)=K_{P}+\frac{2 K_{r} \omega_{c} s}{s^{2}+2 \omega_{c} s+\omega^{2}}$

\subsection{Harmonic stability analysis of multilevel inverters tied to the grid}

The block diagram of overall system is shown in Figure 8 and its corresponding Matlab-Simulink diagram is presented in Figure 9. A capacitor bank of $12 \mu \mathrm{F}$ is connected parallel at PCC. Grid specifications are taken as $400 \mathrm{~V}, 50 \mathrm{~Hz}$ and impedance $Z g=(0.1+j 400) \Omega$. A PR controller is used to drive the inverter and an LCL filter is used to improve the quality of grid current [25]-[28]. PWM technique is implemented to produce switching pulses to converter. Specifications and parameters of the five inverters are stated in Table 2.

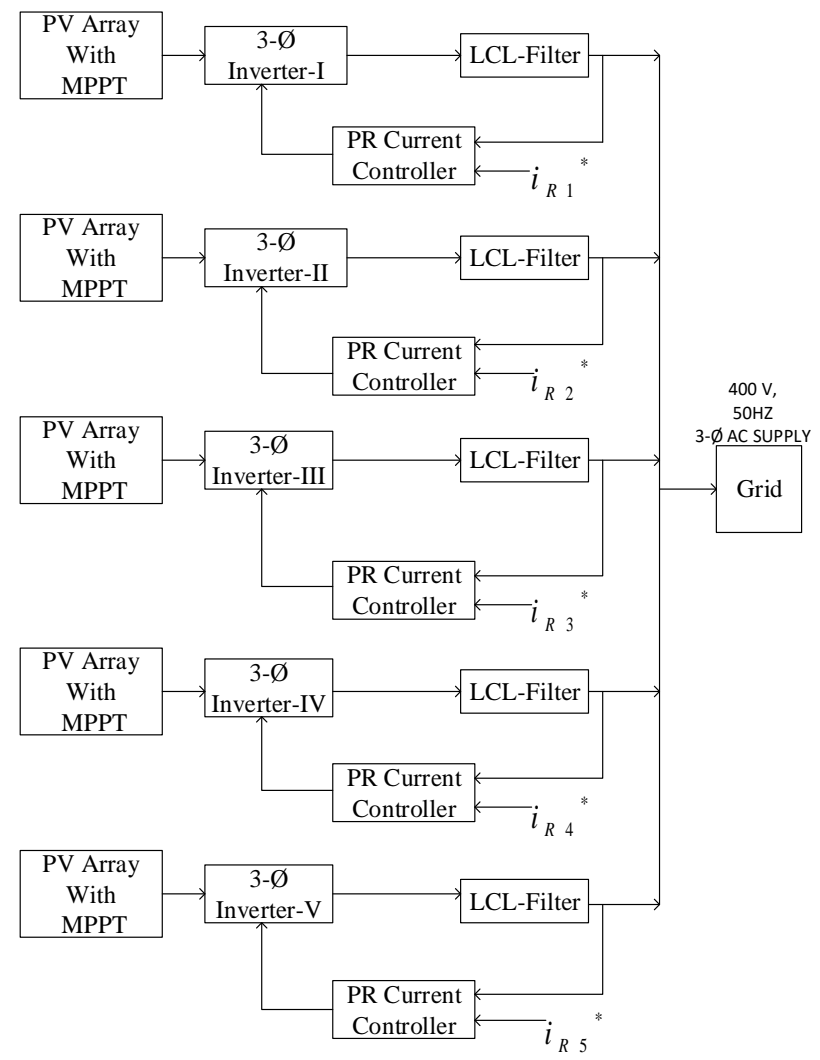

Figure 8. Five PV arrays tied to grid 


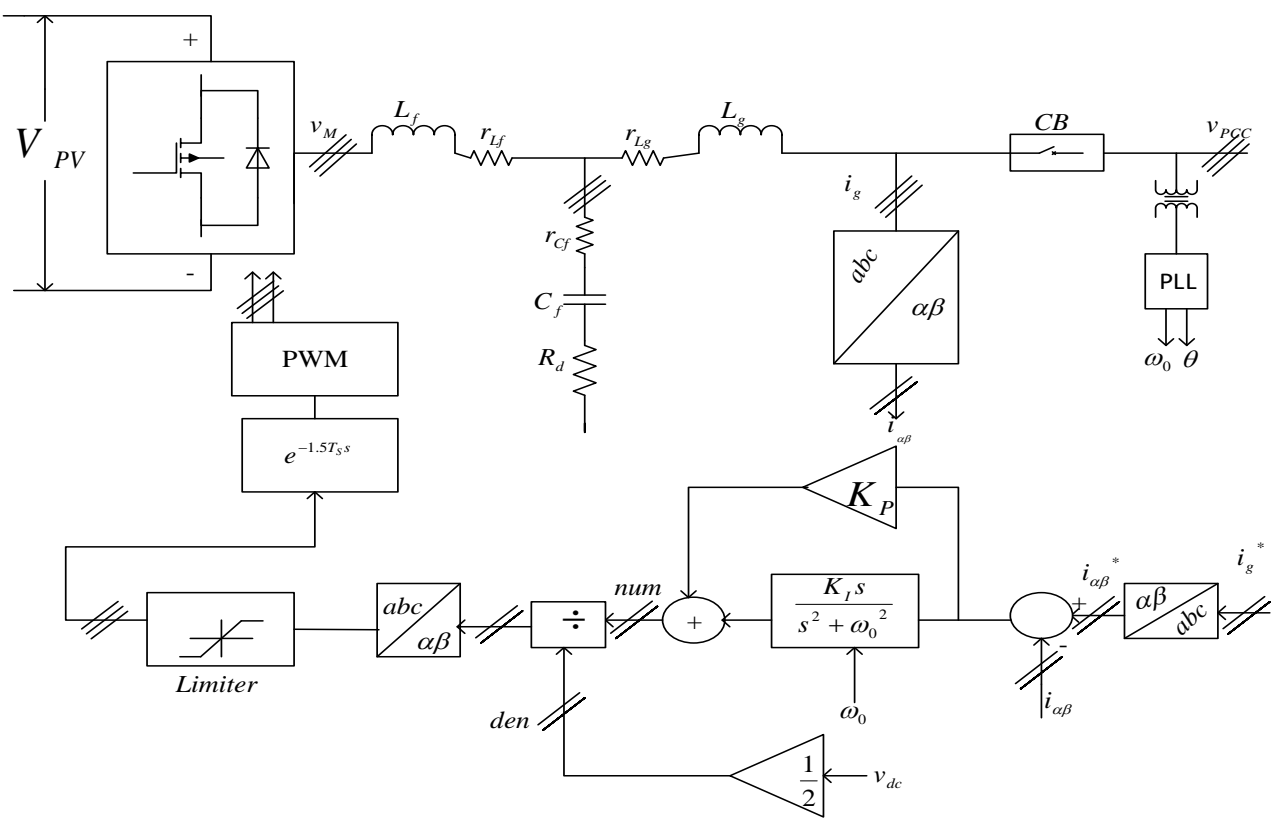

Figure 9. Single line diagram of a PV inverter tied to grid

Table 2. System specifications

\begin{tabular}{ccccccc}
\hline Inverters & Parameters & INV.1 & INV.2 & INV.3 & INV.4 & INV.5 \\
\hline Rating & $\mathrm{KVA}$ & 5.6 & 3.5 & 10.5 & 4.2 & 7 \\
Switching frequency & $\mathrm{KHz}$ & 10 & 10 & 15 & & 10 \\
DC Voltage & & & & $600 \mathrm{~V}$ & & \\
& $\mathrm{~L}_{\mathrm{f}}[\mathrm{mH}]$ & 20 & 22 & 24 & 25 & 15 \\
Filter Values & $\mathrm{C}_{\mathrm{f}}[\mu \mathrm{f}] / \mathrm{r}_{\mathrm{d}}$ & $22 / 0.2$ & $15 / 0.4$ & $2 / 7$ & $3 / 42$ & $15 / 0.9$ \\
& $\mathrm{~L}_{\mathrm{g}}[\mathrm{mH}]$ & 0.22 & 0.3 & 1.7 & 1.3 & 0.2 \\
Parasitic Values & $\mathrm{r}_{\mathrm{Lf}}[\mathrm{mH}]$ & 11.4 & 15.7 & 66.8 & 49.7 & 10 \\
& $\mathrm{r}_{\mathrm{Cf}}[\mathrm{mf}]$ & 7.5 & 11 & 21.5 & 14.5 & 11 \\
Control Gain & $\mathrm{r}_{\mathrm{Lg}}[\mathrm{m} \Omega]$ & 2.9 & 3.9 & 22.3 & 17 & 2.5 \\
& $\mathrm{~K}_{\mathrm{p}}$ & 5.6 & 8.05 & 28.8 & 16.6 & 5.6 \\
& $\mathrm{~K}_{\mathrm{I}}$ & 1000 & 1500 & 1500 & 1000 & 1000 \\
\hline
\end{tabular}

The expression for source admittance is given in the (8).

$$
Y_{S G}=\frac{1}{R_{S}+s L_{S}}
$$

where $R_{S}$-Grid resistance, $L_{S}$-Grid inductance

The expression for source admittance is depicated in (9)

$$
Y_{L G}=S Y_{C P F C}+Y_{C L 1}+Y_{C L 2}+Y_{C L 3}+Y_{C L 4}+Y_{C L 5}
$$

where $Y_{C P F C}$ denotes the admittance of capacitor CPFC, minor loop gain $T_{M G}$ is obtained as:

$$
Y_{L G}=Y_{C F P C}+\sum_{1}^{5} Y_{C L X}, T_{M G}=\frac{Y_{M G}}{Y_{L G}}
$$

The minor loop gain $\left(\mathrm{T}_{\mathrm{MG}}\right)$ is highly depending on the load admittance given by (10). In this study, load impedance is assumed to be constant. It means that all 5 inverters are tied to the grid and grid inductance is varied from $1 \mathrm{mH}$ to $1000 \mathrm{mH}$, with the grid resistance constant. If the MLG of the overall system obeys the Nyquist stability criteria for different values of grid impedance, then the system is harmonically stable, otherwise overall system is said to be unstable. 


\section{SIMULATION RESULTS AND DISCUSSION}

Two different case studies are considered to examine the harmonic stability analysis with the above defined system parameters given in Table 2, where five PV inverters are tied to the grid. In first case study, grid impedance is variable and load impedance is constant. In the second case study, load impedance are variable and grid impedance is constant at $Z g=(0.1+j 400) \Omega$.

\subsection{Case study 1: Constant grid resistance and varying grid inductance}

\subsubsection{Grid inductance up to $5 \mathrm{mH}$}

Here grid resistance is kept constant and grid inductance is varied. The system becomes stable upto $\mathrm{L}_{\mathrm{S}}=5 \mathrm{mH}$. In this case all the 5 inverters are tied to grid. The grid iducatance $L S=5 \mathrm{mH}$, total grid current is 44A. Nyquist Plot of the minor loop gain and the simulation results of THD of grid current, grid curent wave form, individual individual inverter currents, \% THD of the grid currents for the overal system are shown in Figure 10 to Figure 13. respectively.

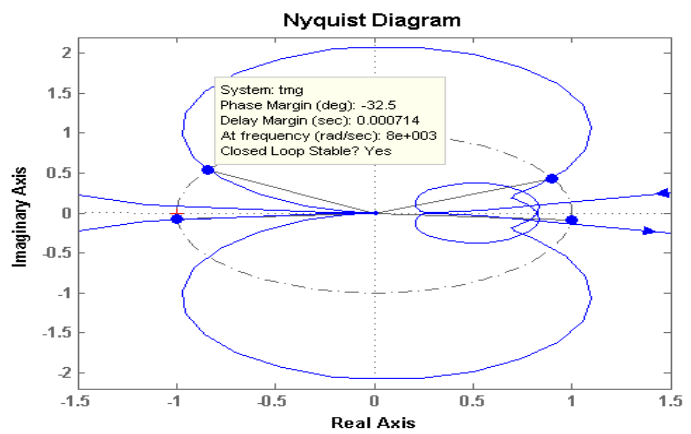

Figure 10. Nyquist plot of minor loop gain

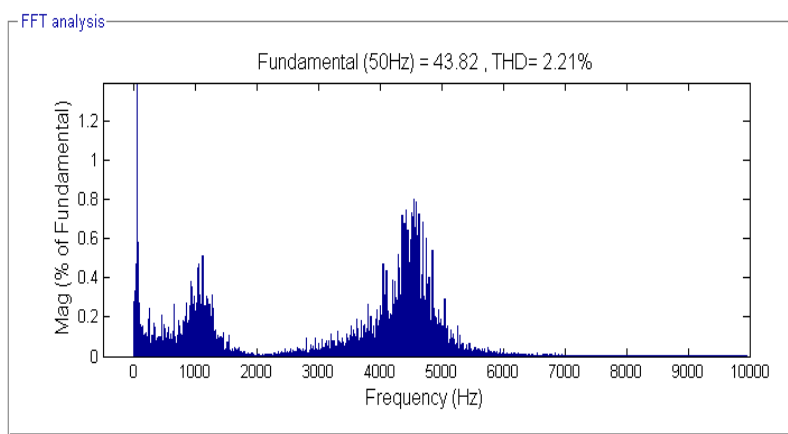

Figure 11. THD analysis of the grid current with grid inducatane upto $5 \mathrm{mH}$

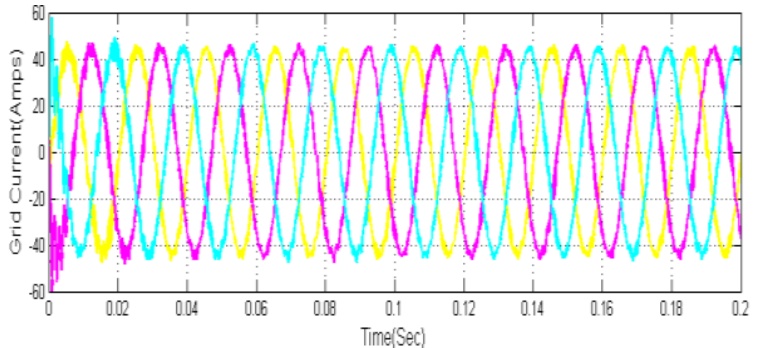

Figure 12. Grid current (in Amp)

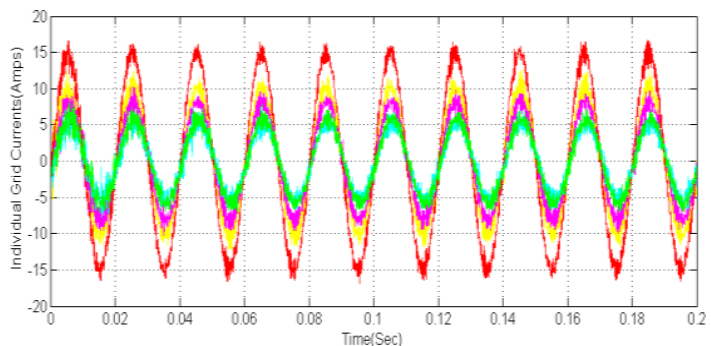

Figure 13. Individual inverter currents (in Amp)

\subsubsection{Grid inductance more than $5 \mathrm{mH}$}

This case is used to illustrate when the grid inductance $\left(\mathrm{L}_{S}\right)$ is more than $5 \mathrm{mH}$. The overall system becomes unstable. Nyquist Plot of minor loop gain with gird inductance value $L S=6 \mathrm{mH}$ is shown in Figure 14. \% THD of the grid current, Grid current and inverter currents are shown in Figure 15, 16, 17 respectively. 


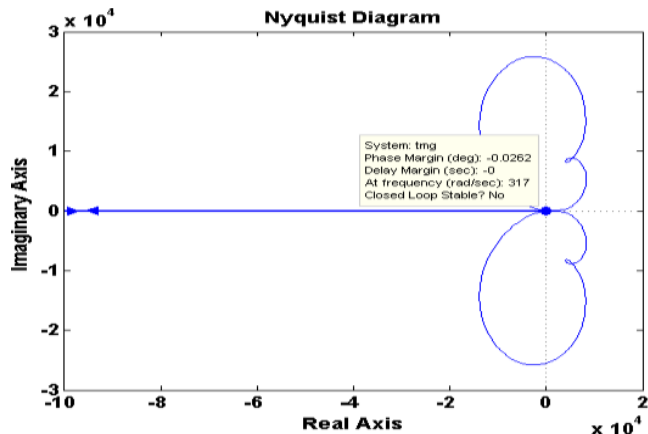

Figure 14. Nyquist plot of minor loop gain with $L_{s}=6 m H$

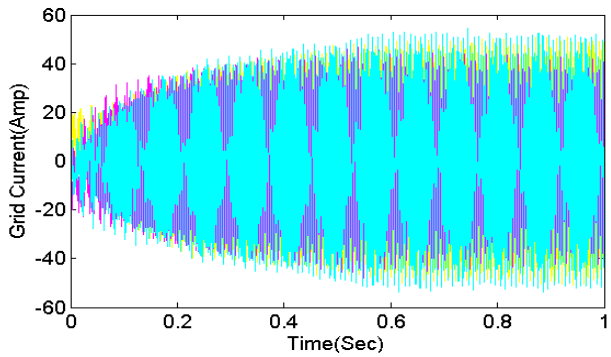

Figure 16. Grid current (Amp)

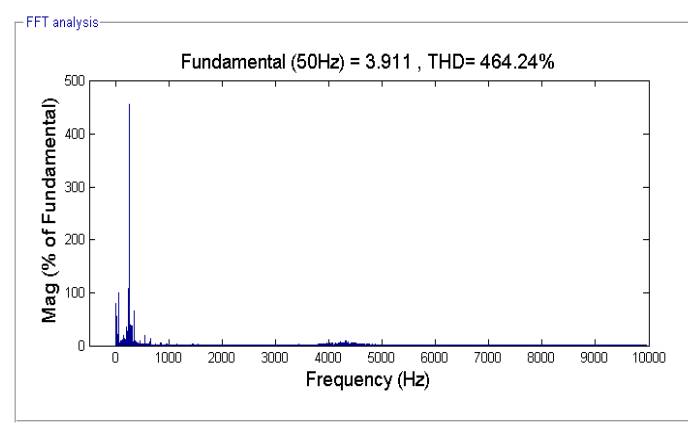

Figure 15. THD response of the grid current

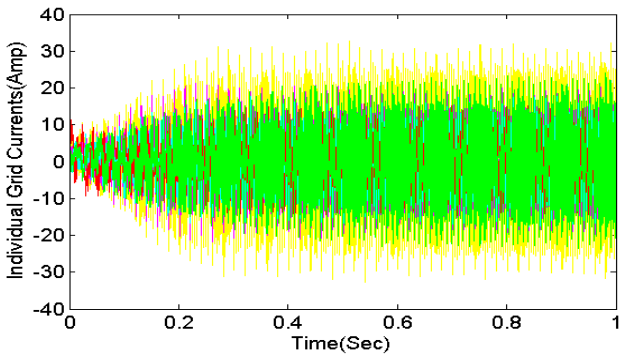

Figure 17. Individual inverter currents (Amp)

\subsection{Case study 2: Constant grid impedance with varying load admittance}

In in practical suitutions there is is possibility of change in load admittance will changes de to te disconnection inverter from grid. Thereby affects the overall system stability. To analyze this situation when INVs are removed from the grid, two cases are considered. In first case, INV 1 is removed and in case B INVs 1,5 are removed. The constant grid impedance is $Z g=(0.1+j 400)$ and the reference is INV 1 given in (11).

$$
Y_{S A}=Y_{C L 1}
$$

Calculation for MLG in this case is given in (13).

$$
\begin{aligned}
& Y_{L A}=Y_{G}+Y_{C P F C}+Y_{C L 2}+Y_{C L 3}+Y_{C L 4}+Y_{C L 5} \\
& \text { Minor loop gain of the system } T_{M A}=\frac{Y_{S A}}{Y_{L A}}
\end{aligned}
$$

In First case, the INV 2, INV 3, INV4, and INV 5 are injecting the currents of 8A, 5A, 15A, and 6A respectively into grid. So total grid current 34A. Nyquist plot of MLG of the system is depicated in Figure 18. From IBSC, it is concluded that the system is stable. The quality of the grid current is $2.37 \%$ as illustrated in Figure 19. Total grid current and individual inverter currents are shown in Figure 20 and Figure 21 respectively. 


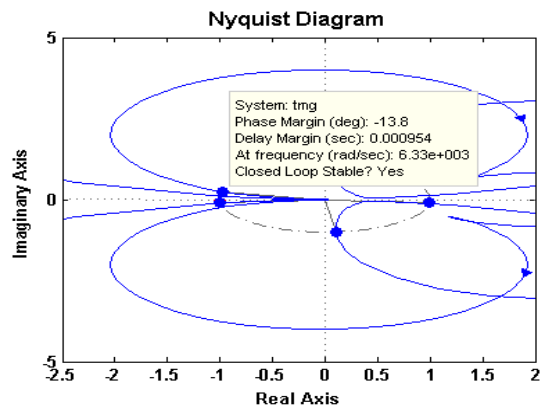

Figure 18. Nyquist plot of system INV -1 OFF

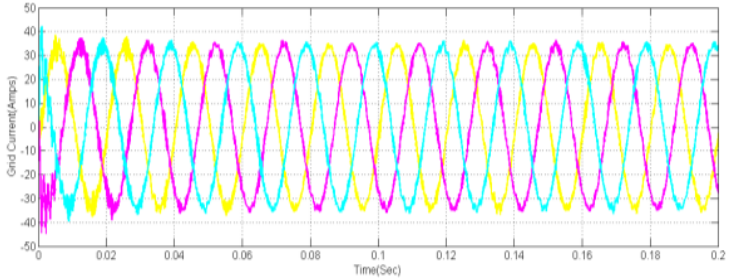

Figure 20. Grid current (Amp)

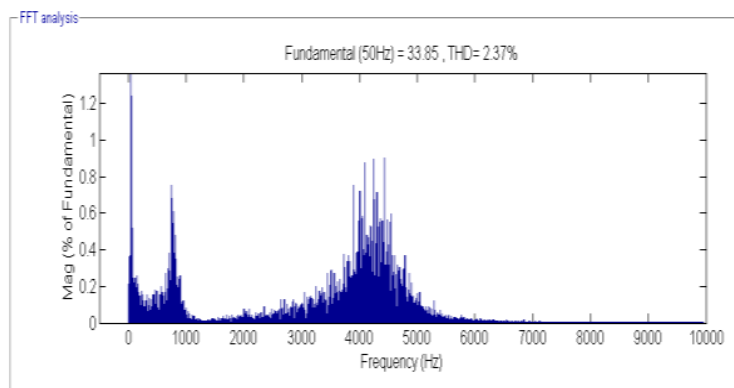

Figure 19. THD response of the grid current

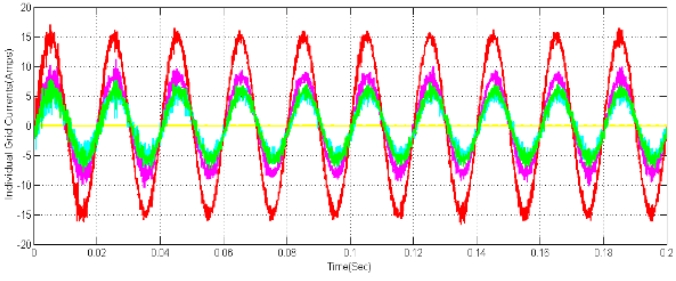

Figure 21. Individual inverter currents (Amp)

In this case INV $1 \&$ INV5 are disconnected from grid. Nyquist plot of MLG of the system is given in Figure 22. From IBSC, the system is stable. The Quality of the grid current is given in Figure 23. Grid current and individual inverter currents are shown in Figure 24 and Figure 25 respectively.

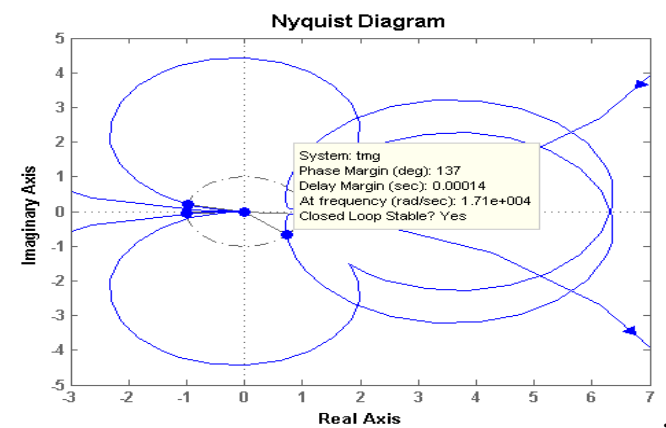

Figure 22. Nyquist plot of INV $1 \& 5$ are disconnected

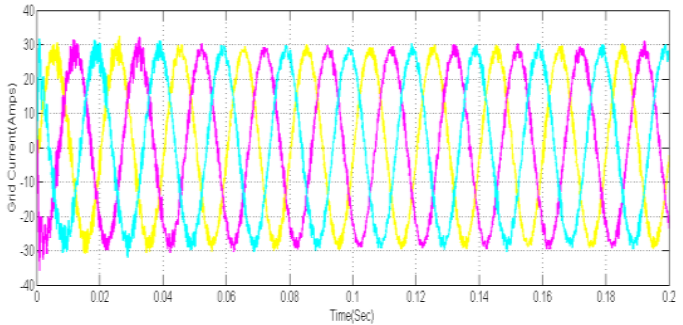

Figure 24. Grid current (Amp)

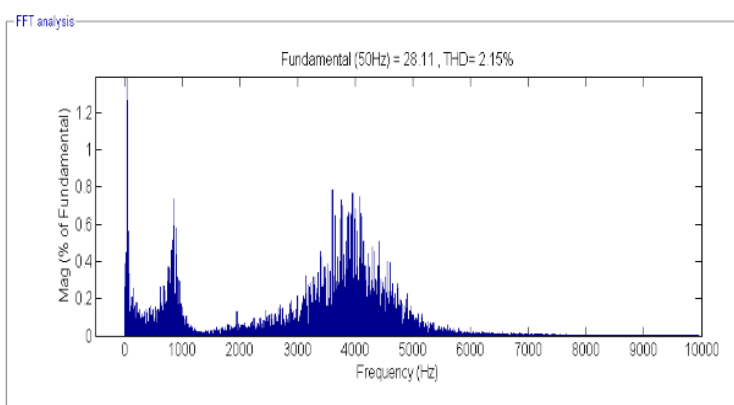

Figure 23. THD response of the grid current

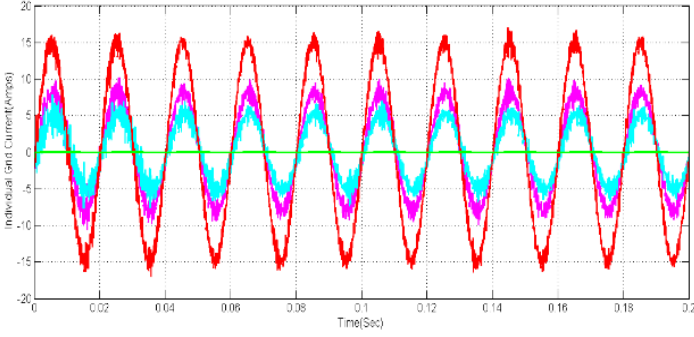

Figure 25. Individual grid current (Amp) 


\section{CONCLUSION}

In this work, investigation of harmonic Stability of multiple PV fed 3-Ø INV is tied to grid is confirmed by new impedance based stability criterion (IBSC). Stability of the system is investigated by varying the grid inductance with constant grid resistance and also by varying load impedance and maintaining grid inductance constant. It was observed that overall system is stable up to grid inductance of $5 \mathrm{mH}$ and above this value, the system becomes unstable. It is also demonstrated that stability of the system depends on grid impedance only and does not depend on load impedance. It is substantiated by means of graphical analysis and Matlab Simulations.

\section{REFERENCES}

[1] X. Wang, F. Blaabjerg and W. Wu, "Modeling and Analysis of Harmonic Stability in an AC Power-ElectronicsBased Power System," in IEEE Transactions on Power Electronics, vol. 29, no. 12, pp. 6421-6432, Dec. 2014, DOI: 10.1109/TPEL.2014.2306432.

[2] X. Wang, F. Blaabjerg, M. Liserre, Z. Chen, J. He and Y. Li, "An Active Damper for Stabilizing PowerElectronics-Based AC Systems," in IEEE Transactions on Power Electronics, vol. 29, no. 7, pp. 3318-3329, July 2014, DOI: 10.1109/TPEL.2013.2278716.

[3] J. H. R. Enslin and P. J. M. Heskes, "Harmonic interaction between a large number of distributed power inverters and the distribution network," IEEE 34th Annual Conference on Power Electronics Specialist, 2003. PESC '03., 2003, pp. 1742-1747 vol.4, DOI: 10.1109/PESC.2003.1217719.

[4] "IEEE Recommended Practice and Requirements for Harmonic Control in Electric Power Systems," in IEEE Std 519-2014 (Revision of IEEE Std 519-1992), pp.1-29, 11 June 2014, DOI: 10.1109/IEEESTD.2014.6826459..

[5] R. D. Middlebrook, "Input filter considerations in design and application of switching regulators,"in Proc.IEEE IAS Annu. Meeting, 1976, pp.366-382.

[6] Xiaogang Feng, Jinjun Liu and F. C. Lee, "Impedance specifications for stable DC distributed power systems," in IEEE Transactions on Power Electronics, vol. 17, no. 2, pp. 157-162, March 2002, DOI: 10.1109/63.988825.

[7] C. Zhang, M. Molinas, S. Føyen, J. A. Suul and T. Isobe, "Harmonic-Domain SISO Equivalent Impedance Modeling and Stability Analysis of a Single-Phase Grid-Connected VSC," in IEEE Transactions on Power Electronics, vol. 35, no. 9, pp. 9770-9783, Sept. 2020, DOI: 10.1109/TPEL.2020.2970390.

[8] W. Zhou, Y. Wang, R. E. Torres-Olguin and Z. Chen, "Effect of Reactive Power Characteristic of Offshore Wind Power Plant on Low-Frequency Stability," in IEEE Transactions on Energy Conversion, vol. 35, no. 2, pp. 837 853, June 2020, DOI: 10.1109/TEC.2020.2965017.

[9] K. Ji, G. Tang, J. Yang, Y. Li and D. Liu, "Harmonic Stability Analysis of MMC-Based DC System Using DC Impedance Model," in IEEE Journal of Emerging and Selected Topics in Power Electronics, vol. 8, no. 2, pp. 1152-1163, June 2020, DOI: 10.1109/JESTPE.2019.2923272.

[10] J.Wyatt, L. Chua, J. Gannett, I. Goknar and D. Green, "Energy concepts in the state-space theory of nonlinear nports:PartI-passivity," IEEE Trans.Circuits Syst., vol. 28, no. 1, pp. 48-61, Jan. 1981.

[11] Zahedi, "A review of drivers, benefits, and challenges in integrating renewable energy sources into electricity grid," Renewable and Sustainable Energy Reviews, vol. 15, no. 9, pp. 4775-4779, 2011, DOI: 10.1016/j.rser.2011.07.074.

[12] M. Castilla, J. Miret, J. Matas, L. Garcia de Vicuna and J. M. Guerrero, "Control Design Guidelines for SinglePhase Grid-Connected Photovoltaic Inverters With Damped Resonant Harmonic Compensators," in IEEE Transactions on Industrial Electronics, vol. 56, no. 11, pp. 4492-4501, Nov. 2009, DOI: 10.1109/TIE.2009.2017820.

[13] S. Eren, M. Pahlevani M. Castilla, J. Miret, J. Matas, L. Garcia de Vicuna and J. M. Guerrero, "Control Design Guidelines for Single-Phase Grid-Connected Photovoltaic Inverters With Damped Resonant Harmonic Compensators," in IEEE Transactions on Industrial Electronics, vol. 56, no. 11, pp. 4492-4501, Nov. 2009, DOI: 10.1109/TIE.2009.2017820.

[14] S. Eren, M. Pahlevaninezhad, A. Bakhshai and P. K. Jain, "Composite Nonlinear Feedback Control and Stability Analysis of a Grid-Connected Voltage Source Inverter With LCL Filter," in IEEE Transactions on Industrial Electronics, vol. 60, no. 11, pp. 5059-5074, Nov. 2013, DOI: 10.1109/TIE.2012.2225399.

[15] Sankar, R.R.S. \& Kumar, J.S.V. and Rao, M.G., "Adaptive Fuzzy PI Current Control of Grid Interact PV Inverter," International Journal of Electrical and Computer Engineering (IJECE), vol. 8, no. 1, pp. 472-482, 2018. DOI: 10.11591/ijece.v8i1.pp472-482.

[16] Sankar, R.S., Kumar, S.V. and Deepika, K.K., "Flexible Power Regulation of Grid-Connected Inverters for PV Systems Using Model Predictive Direct Power Control," Indonesian Journal of Electrical Engineering and Computer Science, Vol. 4, no. 3, pp. 508-519, 2016, DOI: /10.11591/ijeecs.v4.i3.pp508-519.

[17] RS Ravi Sankar, SV Jaya Kumar and KK Deepika, "Model Predictive Current Control of Grid Connected PV System," Indonesian Journal of Electrical Engineering and Computer Science, Vol. 2, no. 2, pp. 285-296, 2016, DOI: 10.11591/ijeecs.v2.i2.pp285-296.

[18] S. U. Ramani, S. K. Kollimalla and B. Arundhati, "Comparitive study of P\&O and incremental conductance method for PV system," 2017 International Conference on Circuit, Power and Computing Technologies (ICCPCT), Kollam, 2017, pp. 1-7, DOI: 10.1109/ICCPCT.2017.8074198. 
[19] G. Petrone, G. Spagnuolo and M. Vitelli, "A Multivariable Perturb-and-Observe Maximum Power Point Tracking Technique Applied to a Single-Stage Photovoltaic Inverter," in IEEE Transactions on Industrial Electronics, vol. 58, no. 1, pp. 76-84, Jan. 2011, DOI: 10.1109/TIE.2010.2044734.

[20] C. Yoon, X. Wang, F. M. Faria da Silva, C. L. Bak and F. Blaabjerg, "Harmonic stability assessment for multiparalleled, grid-connected inverters," 2014 International Power Electronics and Application Conference and Exposition, 2014, pp. 1098-1103, DOI: 10.1109/PEAC.2014.7038014.

[21] J. L. Agorreta, M. Borrega, J. López and L. Marroyo, "Modeling and Control of NN -Paralleled Grid-Connected Inverters With LCL Filter Coupled Due to Grid Impedance in PV Plants," in IEEE Transactions on Power Electronics, vol. 26, no. 3, pp. 770-785, March 2011, DOI: 10.1109/TPEL.2010.2095429.

[22] H. Komurcugil, N. Altin, S. Ozdemir and I. Sefa, "Lyapunov-Function and Proportional-Resonant-Based Control Strategy for Single-Phase Grid-Connected VSI With LCL Filter," in IEEE Transactions on Industrial Electronics, vol. 63, no. 5, pp. 2838-2849, May 2016, DOI: 10.1109/TIE.2015.2510984.

[23] G. Shen, X. Zhu, J. Zhang and D. Xu, "A New Feedback Method for PR Current Control of LCL-Filter-Based Grid-Connected Inverter," in IEEE Transactions on Industrial Electronics, vol. 57, no. 6, pp. 2033-2041, June 2010, DOI: 10.1109/TIE.2010.2040552.

[24] M. Venkatesan, R. Rajeshwari, N. Deverajan and M. Kaliyamoorthy, "Comparative Study of Three Phase Grid Connected Photovoltaic Inverter Using PI and Fuzzy Logic Controller with Switching Losses Calculation," International Journal of Power Electronics and Drive Systems (IJPEDS), vol. 7. No. 2, pp. 543-550, 2016. DOI: 10.11591/ijpeds.v7.i2.pp543-550.

[25] Cao, Wenchao, "Impedance-Based Stability Analysis and Controller Design of Three-Phase Inverter-Based Ac Systems." PhD diss., University of Tennessee, 2017. https://trace.tennessee.edu/utk_graddiss/4449

[26] J. Sun, "Impedance-Based Stability Criterion for Grid-Connected Inverters," in IEEE Transactions on Power Electronics, vol. 26, no. 11, pp. 3075-3078, Nov. 2011, DOI: 10.1109/TPEL.2011.2136439.

[27] X. Wang, F. Blaabjerg and W. Wu, "Modeling and Analysis of Harmonic Stability in an AC Power-ElectronicsBased Power System," in IEEE Transactions on Power Electronics, vol. 29, no. 12, pp. 6421-6432, Dec. 2014, DOI: 10.1109/TPEL.2014.2306432.

[28] KK Deepika,GKRao, J Vijaya Kumar, and RS Ravi Sankar, "Enhancement of Voltage Regulation using a 7-Level Inverter based Electric Spring with Reduced Number of Switches," Indonesian Journal of Power Electronics and Drive Systems (IJPEDS), Vol. 11, no. 2, pp. 555-565, 2020, DOI: 10.11591/ijpeds.v11.i2.pp555-565.

\section{BIOGRAPHIES OF AUTHORS}
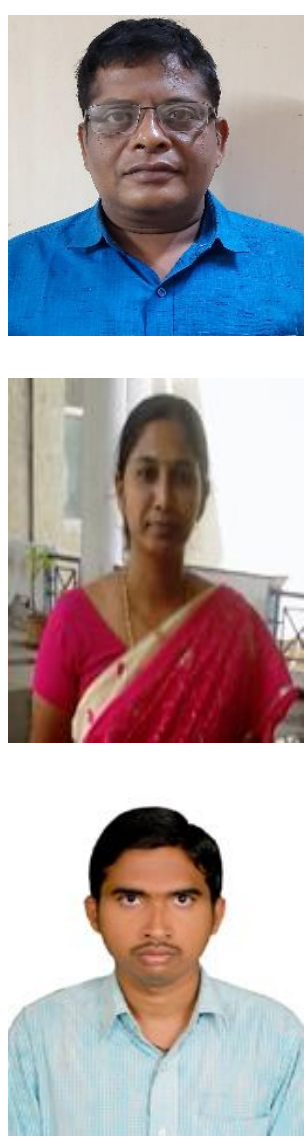

Dr. R.S. Ravi Sankar Currently working as Associate Professor in the department of EEE in Vignan's Institute of InformationTechnology, Visakhapatnam, Andhra Pradesh, India. Received his Bachelors, Masters and Doctoral degree from Institution of Engineers, JNTU Hyderabad, JNTUA Ananthapuram. His research interests include power quality in distribution systems, Renewable energy Sources, electric drives.

K.K. Deepika is currently pursuing her $\mathrm{Ph}$. D. degree in Electrical Engineering at KLEF, Vijayawada, Andhra Pradesh, India. She is working as Assistant Professor in the Department of EEE in Vignan's Institute of InformationTechnology, Visakhapatnam, Andhra Pradesh, India. Her research interests include power quality in distribution systems, Renewable energy Sources and Demand Side Management.

AV Satyanarayana is currently working as Assistant Professor in the Department of EEE in Vignan's Institute of InformationTechnology, Visakhapatnam, Andhra Pradesh, India. Received his Bachelors, Masters and Doctoral degree from Institution JNTU Kainaa. His research interests include Renewable energy Sources, electric vehicles, optimization techniques. 